Document downloaded from:

http://hdl.handle.net/10251/123505

This paper must be cited as:

Santarremigia, FE.; Molero, GD.; Poveda-Reyes, S.; Aguilar Herrando, J. (2018). Railway safety by designing the layout of inland terminals with dangerous goods connected with the rail transport system. Safety Science. 110:206-216.

https://doi.org/10.1016/j.ssci.2018.03.001

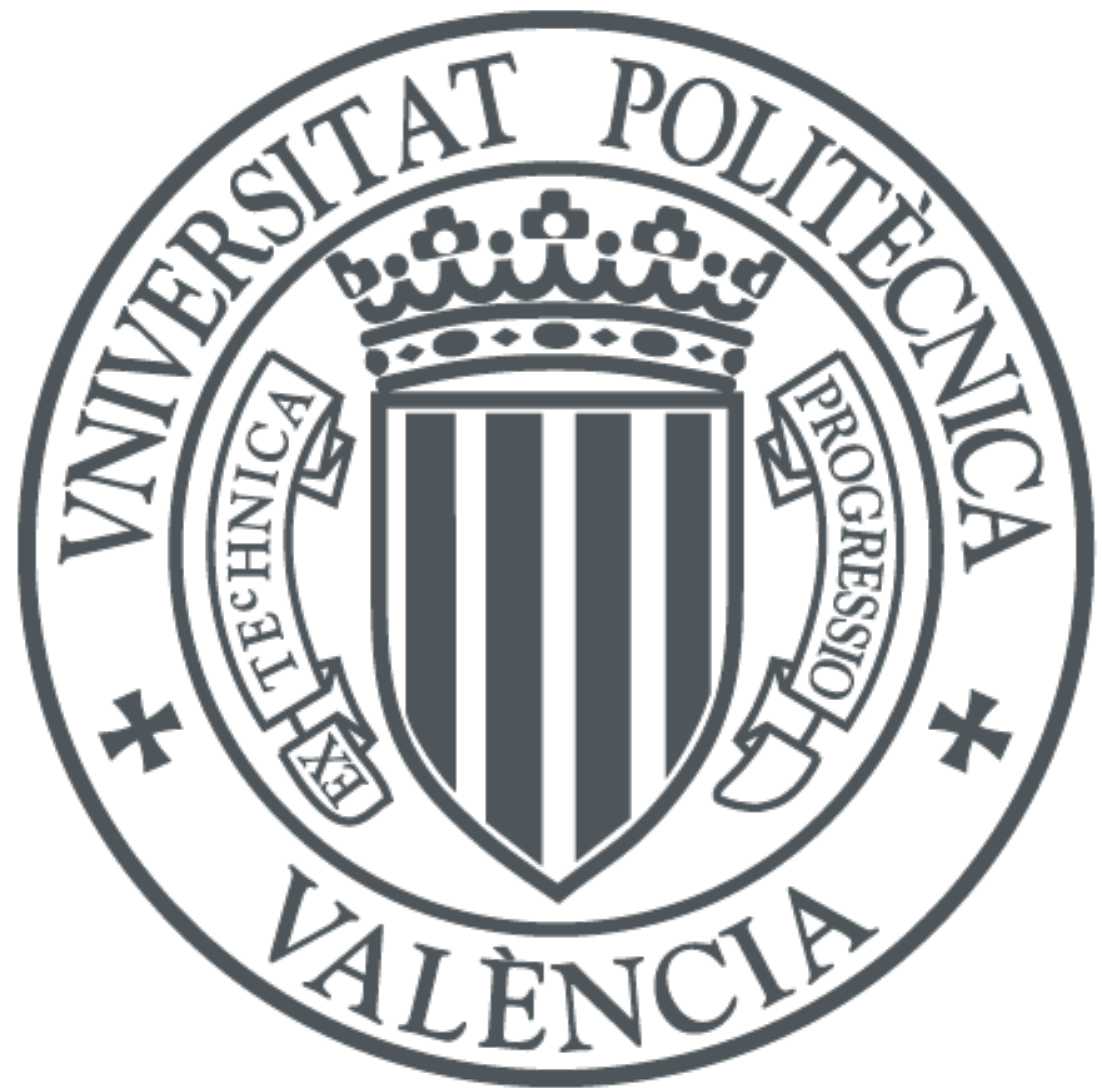

The final publication is available at

https://doi.org/10.1016/j.ssci.2018.03.001

Copyright Elsevier

Additional Information 


\title{
Railway safety by designing the layout of inland terminals with dangerous goods connected with the rail transport system
}

\author{
Francisco Enrique Santarremigia ${ }^{\mathrm{a}, *}$, Gemma Dolores Molero ${ }^{\mathrm{a}}$, Sara Poveda-Reyes ${ }^{\mathrm{a}}$, José Aguilar-Herrando ${ }^{\mathrm{b}}$
}

${ }^{a}$ Dpt. de Proyectos de I+D+i, AITEC Parque Tecnológico, C/ Charles Robert Darwin, 20, 46980 Paterna, Valencia, Spain b Dpt. de Ingeniería e infraestructura de los transportes, Universitat

Politècnica de València, Camino de Vera, s/n, 46022 Valencia, Spain

\section{A R TICLEINFO}

\section{Keywords:}

Railway safety

Dangerous goods

Inland terminal

Security

Layout

Multicriteria decision

AHP

\begin{abstract}
While rail transport is growing for medium-distance journeys, the first and last miles are travelled by road, marking a change of transport mode in inland terminals (ITs). Moreover, the introduction of ITs in seaport hinterlands is increasing with a view to decongesting ports, and the best transport mode to connect these ITs with ports is that of rail.

In 2013, chemicals were involved in 48 rail accidents in the EU-28 and in 667 in the United States (US). An appropriate design for the layout of inland terminals for containers with dangerous goods (ITDGs) involved in the rail system will increase the safety and operability of rail transport, avoiding accidents such as Tianjin (2015).

The novelty of this work is a methodology to design the layout of ITDGs involved in rail transport through a hierarchy of container handling equipment (CHE), used in the yard of the terminal for a safer, more resilient and more environmentally friendly rail transport.

The AHP (analytic hierarchy process) was used to hierarchize five alternative layouts, one for each CHE used in the yard; and according to criteria belonging to three areas: safety and security, environment and equipment performance. Results show that a layout linked to platforms is the preferred alternative for storing containers with dangerous goods (DGs) in ITs connected to railways.

The implementation of this methodology will reduce consequences in the case of a serious accident in, or terrorist attack on, ITDGs involved in the rail system and GHG (greenhouse gas) emissions in the terminal.
\end{abstract}

\section{Introduction}

From 1995 until 2013, the transport of goods increased by 13.8\% (from 3060 billion tonne-kilometres (t. km) in 1995 to 3481 billion t. km in 2013) in the EU28, of which 406.50 billion t $\cdot \mathrm{km}$ (11.7\%) were transported by rail in 2013 (European Union Road Federation, 2016). In the case of the United States (US), from 2012 until 2015 the transport of goods increased by 5\% (from 7098 billion t $\cdot \mathrm{km}$ in 2012 to 7473 billion $\mathrm{t} \cdot \mathrm{km}$ in 2015) (United States Department of Transportation, 2017). The most remarkable increase has been in China, where freight transport from 2006 (with 8883 billion t $\cdot \mathrm{km}$ ) to 2015 (with 17,835 billion $\mathrm{t} \cdot \mathrm{km}$ ) has doubled (National Bureau of Statistics of China, 2017). The increase in the transport of goods produces larger flows of containers that congest seaport operations (Roso et al., 2009). One approach to deal with this increase in transport flow and its associated problems is a joint seaport and hinterland perspective, where rail transport has an important role.

The development of IT, defined as inland facilities directly connected to one or more seaports, where customers can leave and/or pick up their standardized units in the same way as in a seaport and connected with different means of transport (Roso et al., 2009), could play a key role in diminishing the pressure on the inland segment of freight distribution. This will reduce traffic, risk, and associated environmental impacts in regions surrounding ports and may become a relevant element of the supply chain. This is especially true due to the high costs for companies and legal requirements involved in seaport facilities.

The mode of transport (road, barge or rail) used to access the hinterland from the seaport will depend on the distance between them, their availability, the costs and the quality of the service (e.g. transit times). The use of rail transport, from a cost perspective, is the most competitive in distant terminals (more than $300 \mathrm{~km}$ ). However, rail has also been used for close (less than $100 \mathrm{~km}$ ) and mid-range terminals to provide a faster service, and to relieve traffic jams in the surrounding areas and at the gates of the ports, with this solution being more energy efficient and environmentally friendly (Bask et al., 2014).

ITs are widely developed in North America and Europe, and differences between them are based on logistics ownership (public or private), the situation of the market and the history of its development and technology (Rodrigue and Notteboom, 2012). Using trains instead of road transport reduces road traffic to a large extent, since one train can replace 35-100 trucks (Roso et al., 2009). The use of rail transport instead of road transport also produces a reduction in carbon emissions of $64 \%$ (an average of $62 \mathrm{gCO}_{2} / \mathrm{t} \cdot \mathrm{km}$ for road freight transport compared with $22 \mathrm{gCO}_{2} / \mathrm{t} \cdot \mathrm{km}$ for rail transport) (Cefic, 2011). Moreover, $\mathrm{CO}_{2}$ emissions in the terminal constitute around 5\% of emissions over the total rail transport; while the rail transport of 1 TEU (twenty-foot equivalent unit) between Hamburg and

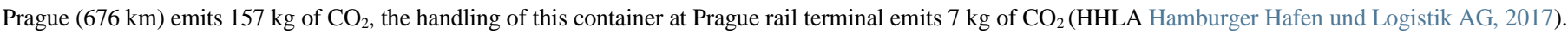

In the particular case of DGs, legal rules concerning safety and environmental storage requirements limit the time they can be held in ports. Moreover, chemicals make up 20\% of the total rail shipments in Europe (DESTINY, 2013), and in 2013, while being transported by rail, they were involved in 48 accidents in the EU28 (Eurostat, 2015) and in 667 accidents in the US (US Department of Transportation PHMSA, 2017). Explosive events during the storage or transportation of chemicals are rare. However, certain products such as ammonium nitrate can explode, what could have devastating consequences such as the accident in Drevja, Norway (2013) (Due-Hansen, 2017). This highlights the importance of an appropriate design for rail ITDGs in order to increase the safety and operability of rail transport. The development and implementation perspectives of ITDGs are very positive regarding the increase in the traffic of exports and imports of chemical products (UNCTAD, 2016), and all the requirements for the ports of the future: green, cost-efficient, safe and secure, resilient and socially inclusive (Zarli et al., 2016).

Given the increasing importance of ITDGs connected with the railway system, it seems necessary to tackle the design of these kinds of logistics facilities in a decision-making process involving relevant stakeholders to increase the safety and environmental care of container rail transport and to reduce the accidentability.

The objective of this manuscript is to study the design of the layout of these rail ITDGs by achieving the following specific objectives:

a. To identify stakeholders related to the decision-making process and to create an appropriate expert panel.

b. To identify criteria involved in the decision-making process and possible layout alternatives.

c. To define a methodology to hierarchize these alternatives taking

into account all relevant points of view. 


\subsection{Design factors involved in ITDGs}

The design and management of efficient container terminals using optimization methods has been increasingly studied during the last few years, especially for the case of maritime ports. These studies have been focused on: equipment performance, environmental care, and safety and security.

\subsubsection{Equipment performance}

Most recent papers published on the topic were focused on container handling equipment (CHE) performance in: a study of costs, an indirect approach based on the minimization of loading-unloading operating time and space optimization.

1.1.1.1. Costs. Lee and Kim (2013) proposed an optimization model to determine the layout of a container yard. The authors considered two types of yard layout when yard cranes were used as CHE. One was a parallel layout in which blocks are laid out parallel to the quay, while the other was a perpendicular layout in which blocks are laid out perpendicular to the quay. The objective was to minimize the total operational cost. When comparing the parallel layout with the perpendicular layout, it was found that the parallel layout is superior to the perpendicular layout in terms of total operational cost.

1.1.1.2. Handling time. With a similar purpose, Wiese et al. (2013) studied the best layout design when using straddle carriers as CHE in order to minimize the cycle times. The results showed that it cannot be concluded that a parallel layout is superior to a perpendicular layout. Said and El-Horbaty (2015) proposed an optimization methodology for solving container handling problems using the genetic algorithm applied to real data from a container terminal at Port Said port in Egypt. The proposed approach reduced the ship service time in the port (loading/unloading) by $56 \%$.

Following this main idea of time saving, Meisel and Bierwirth (2013) tried to minimize the required time for loading and unloading vessels and Alessandri et al. (2008) proposed a dynamic discrete-time model of the flows of containers in maritime terminals. Guo and Huang (2012) proposed a hierarchical scheme for yard crane workload management in container terminals. The scheme combines simulation and optimization to improve the efficiency, minimizing the average vehicle job waiting time at yard side.

1.1.1.3. Space optimization. The high price of the ground surrounding seaports and the expansion difficulties have encouraged researchers to look for smart solutions to minimize the block size of the containers in relation to the different cranes used (Lee and Kim, 2013). To improve the design of the port terminals, Kang et al. (2008) developed a mathematical model that optimized the fleet size to be used in the operations involving containers unloading from the ships, bearing in mind the required space and the number of CHE units. Jin et al. (2016) studied the daily storage yard management problem, dividing it into a storage space allocation problem and a yard crane deployment problem.

\subsubsection{Environmental care}

Some of the recent existing papers developed mathematical models and simulations by evaluating different CHE options with the goal of diminishing the energy expense. Arango et al. (2013) proposed a mathematical model aimed at minimizing the distance covered by the equipment used in the loading and unloading operations; other research was devoted to reducing the broadcasts from the trucks in slow motion, minimizing the patterns of arrival of the trucks (Chen et al., 2013), and the problem of battery autonomy in terminals with automated guided vehicles was tackled too (Bian et al., 2015). He et al. (2015) proposed a yard crane scheduling problem with a view to energy saving. Subsequently, a simulation was designed for evaluating solutions, and exploring the solution space dealing with several kinds of CHE: quay cranes, internal trucks and yard cranes. Yang and Lin (2013) compared different kinds of CHE used in terminals based on the three performance dimensions of working efficiency, energy saving and carbon reduction performances.

\subsubsection{Safety and security}

We can find systematic studies about container handling from a safety point of view (Murdoch and Tozer, 2012) that consider lashing systems and the identification of weaknesses regarding proper stowage and safe working procedures. However, studies on the design of container terminals from a safety and security point of view are very scarce. Peilin et al. (2012) published a book chapter dealing with a layout evaluation index system for ports with DGs based on the analytic hierarchy process (AHP) method. And Glickman and Erkut (2007) estimated critical impact distances of six different chemicals using modeling tools.

The analysis of the state of the art concluded that among the papers dealing with the optimization of the layout of container terminals, authors establish three main areas of interest: equipment performance, environmental care and safety in a minor extent. The design of ITDGs taking into account these three areas in a simultaneous way through the CHE operating has not been carried out.

\subsection{Multicriteria decision analysis}

Multicriteria decision-making (MCDM) techniques like the AHP method used in this paper are useful procedures to apply when there are multiple criteria to take into account and it is necessary to prioritize them in a project management framework (Gogas et al., 2014). The different MCDM methods are based on distinct theoretical foundations such as optimization of results, achievement of an aim or goal, or a combination of these. The common purpose of the diverse techniques is being able to evaluate and choose between several alternatives on the basis of a systematic analysis.

After a literature review and analysis of advantages and disadvantages of available methods (Mulliner et al., 2016; Roy and Słowiński, 2013; Velasquez and Hester, 2013; Zanakis et al., 1998), AHP was selected to develop this study due to: (i) its ease of use, (ii) its intuitive design and scalability, (iii) its ability to simplify the problem in different criteria clusters, resulting in a hierarchy that allows a better understanding of the problem, and (iv) its systematic and traceable method to calculate criteria weights and evaluate the alternatives. However, some disadvantages of AHP are its susceptibility to rank reversal and interdependence between criteria and alternatives (Roy and Słowiński, 2013; Velasquez and Hester, 2013). To solve this, the result robustness needs to be analyzed by calculation of consistency ratios and sensitivity analysis.

In addition, the bibliometric study developed by Tramarico et al. (2015) for MCDM methods applied to the supply chain, in which railway terminals are included, revealed that the multicriteria method most used in publications from 2011 to 2014 is the AHP, making it therefore the appropriate method for this type of study.

In the AHP method (Saaty, 1980, 2013, 2016) criteria prioritization is done by an expert panel where the different stakeholders are involved. Cascetta et al. (2015) defined stakeholders involved in the transport field as "people and organizations who hold a stake in a particular issue, even though they have no formal role in the decision making process". It is possible to find in the literature a considerable growth in the applications of the AHP method to decision-making procedures 
related to infrastructure engineering, and some of them applied to rail transport (Aragonés-Beltrán et al., 2014; Hasan et al., 2012; Montesinos-Valera et al., 2017) and sustainable manufacturing (Harik et al., 2015).

Recently, the application of the method was related to the comparison of different logistic facilities. As an example, Yang (2015) used AHP to determine the degree of importance of green container terminal assessment criteria in order to identify the ranking order of six main commercial ports in the Far East area.

Kayikci (2010) used a combination of fuzzy-AHP and artificial neural network methods to select the best location for an intermodal freight logistics center within given selection alternatives. Golbabaie et al. (2012) applied AHP to compare three layout configurations of a terminal based on their productivity. Costs, flexibility, transfer cycles and storage capacity were the criteria considered, but environmental and safety factors were not taken into account. Jahromi et al. (2012) applied the AHP method for selecting between vertical and horizontal stacking layout types regarding three criteria: management, operational area and operational time.

It is necessary to broaden the existing literature to cover the growing requirements of the global market regarding DGs. In this field, environmental care, safety and security considerations are unavoidable, due to the inherent characteristics of these products, when designing the layout of rail ITDGs.

In the present paper, the rail ITDGs layout design is studied by means of the prioritization of CHE alternatives used in the yard, due to the univocal relationship between CHE and the layout design (Monfort Mulinas et al., 2011). We used the AHP in our research due to its successful application in several knowledge areas (Tramarico et al., 2015) and its suitability for the case being analyzed. Application of AHP contributes to the design of ITDGs with a structured and novel analysis that allows establishing a hierarchy of alternatives and weighing them based on a scientifically contrasted procedure which considers three different study areas in the hierarchical model. Therefore, while a cost benefit analysis only allows comparison between different alternatives for cost and benefit criteria, AHP allows holistic evaluation of alternatives, considering both quantifiable criteria (e.g. costs), and non-quantifiable criteria (e.g. emergency procedures or the automation level of the equipment).

\section{Methodology}

The planned methodology is based on use of the AHP multidecision making method for the prioritization of different yard layout alternatives given different criteria, obtained from a previous work (Molero et al., 2016; Molero Prieto, 2016). This study also used AHP to obtain criteria weights for the design of container terminals with dangerous goods, taking into account five areas of criteria: safety and security, environmental care, equipment performance, information and communication technologies, and business intelligence. Since this work is focused on three of these criteria: safety and security, environmental care, and equipment performance, criteria weights have been normalized from five to three areas, for use in the AHP model. Criteria and their global normalized weights ( $\left.W_{C G k}\right)$ can be seen in Appendix Table 1.

After identifying criteria and obtaining weights, possible alternatives for goal achievement are evaluated taking into consideration all weighted criteria to prioritize them. Thus, criteria and alternatives are elements of decision in the problem that build up the hierarchy model together with the goal.

The working scheme followed in this manuscript is detailed hereafter:

(a) The expert panel was constituted.

(b) Criteria were explained to the members of the expert panel.

(c) The working team established layout alternatives in relation to the used CHE and defined the hierarchical model in order to apply the AHP.

(d) The expert board completed surveys that resulted in alternative matrices of comparison. In these matrices, comparisons were made between alternatives for each criterion, and alternative prioritization was obtained using the mathematical software "Super Decisions".

(e) Finally, we evaluated the robustness of the method by carrying out a sensitivity analysis, which is a valuable method to evaluate rank reversal, a known drawback of AHP.

\subsection{Expertise panel definition}

The expert panel used to identify all possible CHE or layout alternatives and to judge them from the perspective of each criterion was created taking into consideration: (i) stakeholder theory (Reynolds et al., 2006), to avoid conflicts of interest, and (ii) stakeholder management principles (Clarkson Centre for business ethics, 1999). It comprised:

1. A center of technology (AITEC) working on the development of innovative processes in the area of safety and environment regarding DG logistic processes, represented by two expert technicians.

2. Sustainable development institute (IMEDES-Mediterranean Institute for Sustainable Development), represented by the head managing director and a technician.

3. Automatism and information and communication technology company (JOFESA), represented by the head manager and a senior engineer. These experts have wide experience in the control of network systems on a large scale, automatism, machinery, and wireless sensor and robotic solution networks; and participated in the definition and analysis linked to equipment of rail ITDGs.

4. A logistics operator company specialized in the transport of chemicals and plant-protection products and the owner of an IT devoted to containers of DGs (FITOTRANS), represented by the head manager and the QHSE (quality, health, safety and environment) coordinator. This company has expertise in equipment operating in terminals.

5. Port Institute for Studies and Cooperation (FEPORTS), represented by the research project manager and an engineer. Among their strategic lines we can find the improvement of port system effectiveness in the Valencia region, boosting policies on transport and logistics, and strengthening connections with other European and peripheral regions. This institute assumed an equipment expertise role.

Each of these experienced professionals provided independently completed questionnaires. Consensus was achieved through the use of DELPHI methodology (Linstone and Turoff, 1975). 
For the design of the layout in rail ITDGs we consider five different alternatives according to the kind of CHE to be used in this kind of facility (Lee and Kim, 2013), inasmuch as CHE defines the configuration of a container terminal (Monfort Mulinas et al., 2011).

We considered one kind of CHE operating in the terminal yard and five possible design alternatives for the yard layout (Koppe and Brinkmann, 2008; Santarremigia et al., 2017) (Table 1), in relation to the corresponding yard equipment.

CHE alternatives and their corresponding yard layout are:

A1. Straddle carriers: are vehicles used for lifting, moving and stacking standard containers, carrying the container between their four legs. They can stack up to three containers and in only one row of containers. The containers considered are 20 -foot equivalent unit (TEU) containers. Between the batteries, a corridor from 1.2 to $2.0 \mathrm{~m}$ is required, and in the transversal extremes of the rows, it is necessary to leave another corridor of at least $10 \mathrm{~m}$ to allow the proper movement of the straddle carrier. Straddle carriers can act as equipment to carry the container out between the yard and the gates of the terminal (interconnection equipment).

A2. Forklifts: are vehicles used to move and stack containers for short distances using two forks and a carriage hydraulic system. When forklifts are used, it is possible to make rows of up to two containers of width and five to seven containers in height. Between each volume of batteries of containers, it is necessary to leave a distance of at least $10 \mathrm{~m}$ to allow for the maneuvering of the forklift. Forklifts can also act as interconnection equipment.

A3. Reach stackers: have an arm that catches the container and moves it through short distances very quickly. These vehicles can be used for yard storage purposes and for the transfer of containers between modes of transport. Compared with forklifts, reach stackers have a higher load capacity, better accessibility to stacked containers, higher stability and more versatility. Reach stackers have a yard configuration of three to four TEUs in width and heights of five to seven TEUs, just like in the case of forklifts. Between batteries of containers it is necessary to leave a distance of at least $10 \mathrm{~m}$. Reach stackers act as interconnection equipment.

A4. Platform/flatbed trailers: are trailers specially designed to transport the container in the terminal. Platforms do not allow the stacking of TEUs; therefore, they give place to rows of one container in width and one container in height. Furthermore, as many platforms as containers stored in the yard are needed. This alternative does not act as interconnection equipment, because the external trucks perform this function.

A5. Gantry cranes: also called portal cranes, are specialized cranes that move the containers parallel to the track over the container stacks that they have formed between their legs. This system has a high stacking capacity. Characteristic gantry crane layouts store an average of eight containers by row with heights of five containers. The width of the corridors between batteries of container blocks should be at least $5 \mathrm{~m}$. This equipment does not need yard interconnection facilities either.

$\underline{\text { Table } 1}$

Alternatives for yard layout design based on type of CHE.

\begin{tabular}{|c|c|c|c|}
\hline \multirow[t]{2}{*}{ Alternative code } & \multirow[t]{2}{*}{ Yard equipment alternative } & \multicolumn{2}{|c|}{ Typical layout } \\
\hline & & $\begin{array}{c}\text { TEUs } \\
\text { per row }\end{array}$ & $\begin{array}{l}\text { TEUs per } \\
\text { column }\end{array}$ \\
\hline A1 & $\begin{array}{c}\text { Straddle } \\
\text { Carrier }\end{array}$ & 1 & 3 \\
\hline $\mathrm{A} 2$ & & 2 & 3 \\
\hline $\mathrm{A} 3$ & $\begin{array}{l}\text { Reach } \\
\text { stacker }\end{array}$ & 3 & 3 \\
\hline A4 & Platform & 1 & 1 \\
\hline A5 & Gantry8 & 5 crane & \\
\hline
\end{tabular}

\subsection{Hierarchical model}

The alternatives, together with the three levels of criteria and the main goal, constitute the hierarchical model to apply the AHP (Fig. 1). 2.4. Prioritization process of alternatives

The opinions of the constituted expertise board are available by means of questionnaires filled in by the experts. The collected opinions constitute matrices of comparison using the scale of Saaty (1980). When a skilled expert compares two alternatives, the relative importance of one particular alternative in front of the other is provided. In terms of the preference of the element shown in a row of the matrix regarding the element shown in a column, a numeric value is given to the corresponding element of the matrix. The scale used to fill the comparison matrices is: 
1. Similar. Both elements are equally preferred.

3. Moderate. One element is slightly preferred in front of the other.

5. Strong. One element is strongly preferred in front of the other.

7. Very strong. One element is very strongly preferred when compared with the other.

9. Extreme. An element is fully preferred when compared with the other

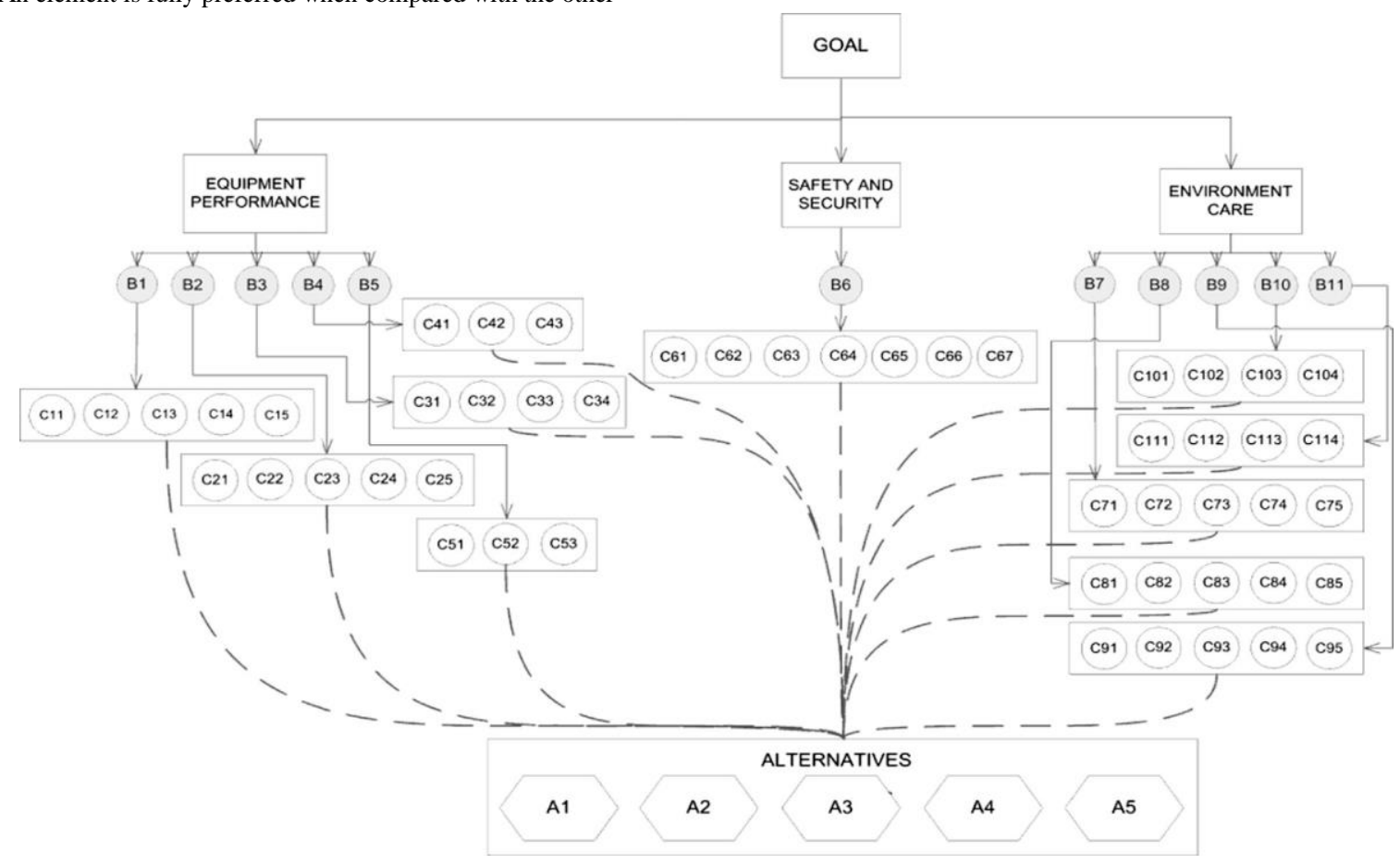

Fig. 1. Hierarchical model proposed.

If, on the other hand, the expert prefers the criterion situated in the column, the value to assign would be the reverse of that previously indicated (1/3, $1 / 5,1 / 7$ and 1/9). Furthermore, experts may use intermediate values such as 2, 4, 6 or 8 if they need to refine their preferences (or 1/2, 1/4, 1/6 and 1/8) (Saaty, 2006).

To prioritize alternatives, the expert panel compared them in pairs for each of the identified criterion. The expert board completed questionnaires in private following the Delphi method (Linstone and Turoff, 1975). The Delphi method is a group structuring method aimed at reaching consensus. After filling in the questionnaires, the answers of the different experts are compared, and where there is a divergence of opinions, a second questionnaire is prepared showing the answers of the first questionnaire and the experts are asked to complete it again taking into consideration the other opinions and reconsidering their answers. This process was repeated several times till achieve a consensus. Further sensitivity analyses supposing minor changes in the judgments of the experts were also carried out (Al-Harbi, 2001).

The data collected constituted matrices of comparison as shown in Table 2. As an example, Table 2 shows the resultant matrix for comparison of five layout alternatives taking into account the preference of experts for the third level criterion personnel cost (C13) of the area equipment performance. When the expert compares two alternatives, a higher value is given to the alternative that has a lower personnel cost. Therefore, the higher the value of $w_{a k}$, the lower the personnel cost and the better alternative compared with the others. As these costs depend on the specific case, the best way to compare alternatives is using MCDM methods, such as AHP, to obtain preferences of those responsible for making decisions in container terminals.

Table 2

Comparison of the alternatives A1 - straddle carrier, A2 - forklift, A3 - reach stacker, A4 - platform and A5 - gantry crane for criterion personnel costs (C13) for the area equipment performance.

\begin{tabular}{lccccccc} 
Personnel Cost (C13) & A1 & A2 & A3 & A4 & A5 & watk \\
\hline A1 & 1 & $1 / 3$ & $1 / 3$ & $1 / 5$ & 3 & 0.0862 \\
A2 & & 1 & 1 & $1 / 3$ & 5 & 0.2010 \\
A3 & & & & 1 & $1 / 3$ & 5 & 0.2010 \\
A4 & & & & & & \\
A5 & & & & 1 & & 0.4691 \\
& & & & & & 1 & 0.0427
\end{tabular}

AHP allows normalized local weights of alternatives to be calculated when compared with the third level criteria $\left(w_{a k}\right)$ from the expert panel survey data. For calculation of normalized local weights $\left(w_{a k}\right)$ of alternative " $\mathrm{t}$ " against criterion " $\mathrm{k}$ ", the following procedure was used:

1. The $n$ alternatives are compared in pairs for each third level criterion using Saaty's scale. These values form a comparison matrix A: 


$$
\begin{aligned}
& A=\left[\begin{array}{cccc}
1 & a_{12} & \ldots & a_{1 n} \\
a_{21} & 1 & \ldots & a_{2 n} \\
\vdots & \vdots & \ddots & \vdots \\
a_{n 1} & a_{n 2} & \ldots & 1
\end{array}\right] \\
& \text { where } a_{j i}=1 / a_{i j} \quad i j,=1, \ldots n
\end{aligned}
$$

2. The consistency ratio (CR) (Eq. (2)) of matrix A (Saaty, 2016, 2013,1980) is used to check inconsistencies

$$
C R=\frac{\left(\lambda_{\max }-n\right) /(n-1)}{R I}
$$

where $\lambda_{\max }$ is the larger or principal eigenvalue of matrix A, $n$ is the size of the matrix and RI is the Random Index, which is an experimental value that depends on $n$ (see Table 3) (Saaty and Ozdemir, 2003). Matrices with a CR of above 0.1 were rejected (Saaty, 1987).

3. The local normalized weight of all alternatives for a third level

Table 3

\begin{tabular}{lllllllll}
\multicolumn{8}{c}{ Random index (RI) values (Saaty and Ozdemir, 2003). } \\
\hline $\boldsymbol{n}$ & 2 & 3 & 4 & 5 & 6 & 7 & 8 \\
\hline
\end{tabular}

$\begin{array}{llllllll}\text { RI } & 0 & 0.52 & 0.89 & 1.11 & 1.25 & 1.35 & 1.40\end{array}$

criterion $\mathrm{k}\left(w_{a 1} k, w_{a 2}, \cdots, w_{a k}, \cdots, w_{a 5 k}\right)$ is the principal eigenvector of the pairwise comparisons matrix $\mathrm{A}$, which is calculated by raising this matrix to a sufficiently large power:

$$
q_{t l}^{z}=\lim _{z \rightarrow \infty} A^{z}
$$

Then summing over the rows and normalizing, we obtain the local normalized weight in the zth power:

$$
w_{a_{t k}}^{z}=\frac{\sum_{l=1}^{n} q_{t l}^{z}}{\sum_{t=1}^{n} \sum_{l=1}^{n} q_{t l}^{z}}
$$

The process was stopped when the difference between $w_{a}^{z} k$ obtained at the zth power and $w_{a z t+k} 1$ obtained at the $(\mathrm{z}+1)$ th power was less than $10^{-4}$.

Moreover, it is especially relevant to obtain a value of the global normalized weight for each alternative versus the main goal that allows the issue to be addressed in a holistic way $\left(W_{A t} G\right)$ was calculated as follows (Eq. (5)):

$$
\begin{gathered}
W_{A_{t}}=\sum_{i=1}^{3}\left[\sum_{j=1}^{n_{i}}\left(\sum_{k=1}^{m_{i j}}\left(w_{c k} \cdot w_{a_{t}}\right) \cdot w_{c j}\right) \cdot w_{c i}\right]=\sum_{i=1}^{3} \sum_{j=1}^{n_{i}} \sum_{k=1}^{m_{i j}} w_{a_{t_{k}}} \cdot W_{C G_{k}} \\
W_{C G_{k}}=w_{c i} \cdot w_{c j} \cdot w_{c k}
\end{gathered}
$$

where $w_{c k}, w_{c j}$, and $w_{c i}$ are the local normalized weights for each criterion of third, second, and first level, respectively.

Weights of each alternative in relation to the first level $\left(w_{a t}\right)$ and the second level $\left(w_{a t}\right)$ criteria can be calculated as follows (Eqs. (7) and (8), respectively):

$$
\begin{gathered}
w_{a_{t_{i}}}=\sum_{j=1}^{n_{i}}\left(\sum_{k=1}^{m_{i j}}\left(w_{c k} \cdot w_{a_{t_{k}}}\right) \cdot w_{c j}\right) \\
w_{a_{t_{j}}}=\sum_{k=1}^{m_{i j}}\left(w_{c k} \cdot w_{a_{t_{k}}}\right)
\end{gathered}
$$

where: $n_{i}=[5,1,5] ; m_{1 j}=[5,5,4,3,3] ; m_{2 j}=[7] ; m_{3 j}=[5,5,5,4,4]$. 


\section{Results and discussion}

\subsection{Hierarchy of alternatives}

$W_{A t} G$ allowed comparison of the different alternatives for achieving the main goal, considering all criteria with their relative importance in a holistic process (Fig. 2A).

While studying $w_{a k}$ results (Appendix Table 2) it was pointed out that, for all third level criteria for the equipment performance area, the use of platforms (A4) is preferential ahead of other CHE, except for the cost of the floor criterion (C12), inasmuch as platforms require greater surfaces to be used in a terminal yard. Anyway, the higher surface requirements are somehow inherent to DG storage because segregation is required and TEU stacking is not recommended. Furthermore, a platform is perceived as reliable CHE in terms of environmental care, safety and security according to its $w_{a t}$ and its $W_{A t} G$ values (Fig. 2). This is to be expected due to the fact that a platform does not generate excessive waste or exhibit excessive consumption, and it does not generate big direct or indirect emissions. Moreover, for a terminal of containers with dangerous substances, the use of platforms as a storage and disposal system for the terminal ensures there is no accumulation of high risks in small surface areas. Even bearing in mind the higher surface-demanding characteristic of platforms, they are considered the most inexpensive device to be used in terms of automation cost (C11), personnel cost (C13), technical maintenance cost (C14) and expansion related cost (C15).
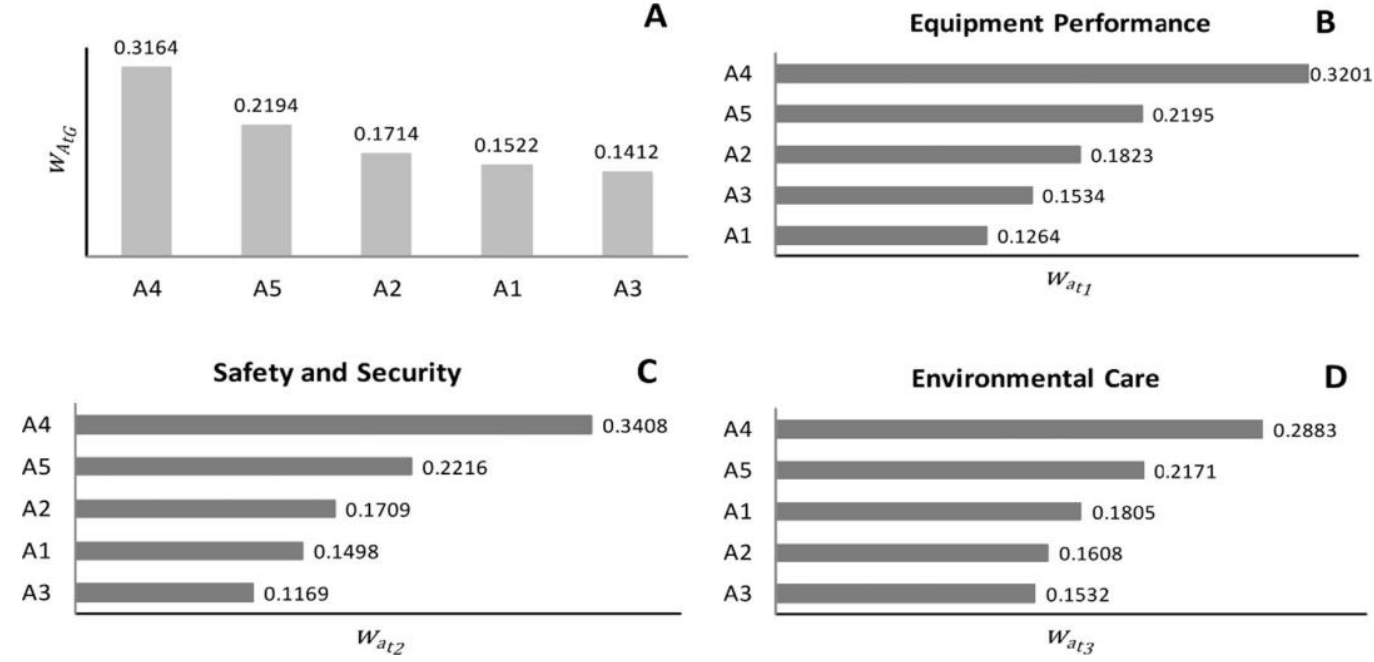

Fig. 2. Prioritization of layout, A1 - straddle carrier, A2 - forklift, A3 - reach stacker, A4 - platform and A5 - gantry crane, in terms of $\boldsymbol{W}_{A t G}(\mathrm{~A})$ or $\boldsymbol{w}_{a t i}$ for equipment performance area (B), safety and security area $(C)$, and environmental care area (D).

This result may seem surprising since platforms are not widely used in Europe in inland terminals involved in the railway transport system, perhaps for two main reasons fundamentally. On the one hand, the criterion related to the cost of the industrial floor traditionally had a high impact on decision-makers because most current ITs can be found relatively near to the port terminals. On the other hand, as the study of the state of the art revealed, the research applied to rail ITDGs seems to be partial and still under development, because papers dealing with a holistic approach to the problem are missed. So, public or private investors cannot enlist technological scientific knowledge that allows them a change to their traditional performances. However, in the United States of America the system of platforms has been widely used for a long time, both in seaports and ITs.

The second preferred yard layout alternative is related to gantry cranes (A5), which are $30 \%$ below the preferred option. We conclude from this, in accordance with the expert panel, that if the option that requires a lower level of investment and lower level of technology is not possible, the option that better satisfies the cost of the floor criteria is preferred. This second option would generate greater battery volumes at the expense of an increase in the risk of potential incidents related to safety and security and environmental care areas. Therefore, the AHP method yielded another apparently surprising result because the gantry crane option is preferred over platforms based on the floor surface needed to dispose of the containers. This is mainly due to the high degree of influence of the criterion cost of the floor (C12). So, when there is an alternative that is significantly better for all the other criteria (i.e. platforms), despite being the worst for the criterion cost of the floor, it becomes the preferred alternative. But if this alternative, which is significantly better for all other criteria, is removed, i.e. platforms cannot be used, there is not another better alternative for most criteria, and the expert panel prefers those alternatives for which the floor cost is optimized, as it is the preferred alternative in the case of gantry cranes. Nowadays, this second option of gantry cranes is used in ITs that have a high capacity for investment, generally public rail ITs.

In third and fourth position, with weights of 55\% and 52\%, respectively, ahead of the preferred layout alternative, come forklift (A2) and straddle carrier (A1). Both contribute to a commitment solution because they achieve intermediate satisfaction in terms of floor surface requirements and the risks associated with the environmental care and safety and security areas. These are the options mainly used at the ITs of small and average size in Spain and Europe. Finally, the reach stacker option is last in the order of preference owing to the risks associated with stacking DGs without achieving an efficient optimization of the surface.

\subsection{Sensitivity analysis}

The sensitivity analysis is performed by analyzing (Ishizaka and Labib, 2011):

i. Variations in alternative ranking when weights of first level criteria are slightly modified.

ii. Variations in alternative ranking when weights of more influential criteria (those weighting 80\%) are slightly modified.

We thought that weight modifications higher than $10 \%$ for the criteria would require reconsideration of the whole process, and it would not constitute a proper sensitivity analysis. The results obtained were quite similar to those achieved originally according to the expertise board opinions. As an example, we show the results of the sensitivity analysis when varying $w_{c i}$ value for the equipment performance area (Fig. 3). The preferred alternative is always a platform for any relative 
value of the equipment performance area, showing the robustness of the AHP method applied. There was a change in the ranking position of straddle carrier and reach stacker, but it happened for variations of $\mathrm{w}_{\mathrm{ci}}$ value higher than $10 \%$. Therefore, it should not be considered.

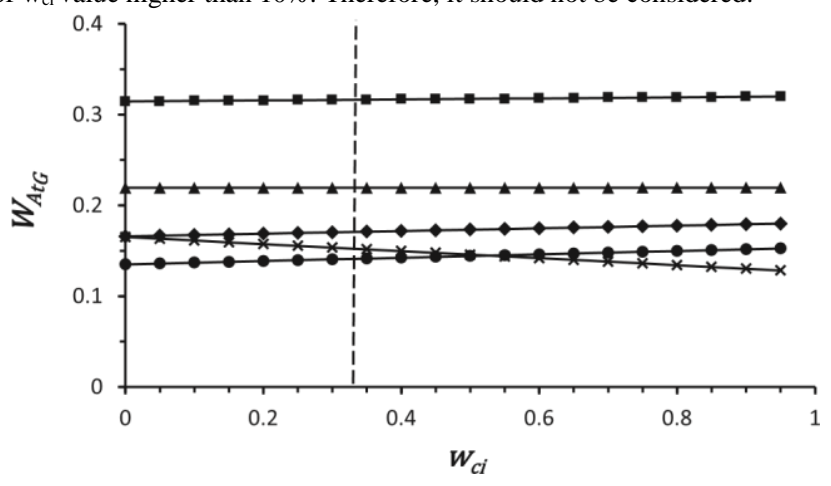

Fig. 3. Global normalized weight of the alternatives A1 - straddle carrier ( $\mathrm{x}$ ), A2 - forklift $(\bullet)$, A3 - reach stacker $(\bullet)$, A4 - platform ( $\bullet$ ) and A5 - gantry crane ( $\Delta$ related to the goal ( $\left.\boldsymbol{W}_{A t G}\right)$ vs. local normalized weight for the first level criterion $\left(w_{c i}\right)$, while varying the local normalized weight of the equipment performance area. Dotted line means $w_{c i}=0.33$ for first level criteria.

The model applied has demonstrated its robustness since when studying the alternative ranking variation in front of the modification of $w_{c i}$, the change of preferences occurred for variations of $w_{c i}$ above $10 \%$, exceeding the acceptable limits for a study of sensitivity.

We also studied the possible variation in the rank of preferred alternatives; this means variations on $W_{A t}$ values, when producing slight modifications on $w_{c k}$ of the most important third level criteria. Those relevant criteria were the criteria that accumulated $80 \%$ of the sum of $W_{C G k}$. We were able to verify that the alternatives A4 - platforms and A5 - gantry crane remained the preferred ones when compared with the main goal after modifying $w_{c k}$ in values lower than $10 \%$. Again, changes in the preference rank were not observed within the acceptable limits established for the sensitivity method.

\section{Conclusion and further developments}

This manuscript contributes with a decision-making methodology addressing the design of the layout of ITDGs involved in the rail transport system in order to increase the safety and environmental care of this kind of terminal without affecting drastically their operability and efficiency.

Management and storage of DGs supported by rail ITs allows a safer and greener rail transport system aimed at avoiding accidents such as Tianjin (2015) (Aitao and Lingpeng, 2017).

The main purpose of this paper is to contribute to the process of designing the layout of rail ITDGs by means of a methodology that would help designers and managers to make decisions in a systematic way. The design of the rail ITDG layout through the prioritization of the used CHE in the yard of the terminal allows us to take a holistic approach and perform global analysis from three main points of view: equipment, environmental care, and safety and security.

The AHP tool provides us with the layout generated by the utilization of platforms as the preferred option. These results have been somehow surprising since the ideal commitment alternative reached is not usual in current rail intermodal terminals.

Nevertheless results are reasonable to the extent that: (i) the rail ITDGs may be placed in not excessively expensive zones; (ii) the platforms do not require a big initial investment or expenditure on automation and maintenance; (iii) the personnel that manipulate the platforms do not require skilled training and therefore the costs are lower; (iv) from a safety and security point of view, this layout option does not generate high accumulations of dangerous substances, thereby decreasing the risk; (v) from an environmental care point of view, this alternative does not imply high consumption with its handling, or generate a high amount of waste or GHG emissions.

The implementation of this methodology will drastically reduce both the consequences in the case of a serious accident/terrorist attack and emissions of GHGs in rail ITs where containers with DGs are present, without incurring additional costs or impacting negatively on the operability of the rail transport.

The design of the rail ITDG layout through the prioritization of the CHE used in the yard has been shown to be an innovative, reliable and robust method by means of sensitivity analysis. This investigation shows a holistic model that should be applied to several case studies. We believe that it would be desirable to spread the results of this investigation among rail terminal managers and designers for a greener, more efficient, safer and more secure multimodal rail transport. Moreover, for a broader improved design of rail ITDGs, it would be interesting to evaluate ICT (information and communication technology) and BI (business intelligence) solutions using the methodology presented in this paper, together with consideration of how the CHE used in the buffer area of the terminal can affect the decisionmaking process regarding the CHE used in the yard of the rail terminal. Another development would be the verification of outcomes through the development of a case of study and/or discrete event simulation to measure and compare Key Performance Indicators (KPIs) for each alternative.

\section{Acknowledgements}

The authors want to acknowledge the Generalitat Valenciana (Spain) for their financial support and the help of the members of the expert board (sorted alphabetically): AITEC, FEPORTS, FITOTRANS, IMEDES, JOFESA. 


\section{Appendix A}

Table A1

Global normalized weights ( $\left.W_{C G K}\right)$ for three criteria areas (equipment performance, safety and security and environmental care) First level criterion: equipment performance

\begin{tabular}{|c|c|c|}
\hline Second level criteria & Third level criteria & $\begin{array}{l}\text { Weight } \\
\left(W_{C G_{k}}\right)\end{array}$ \\
\hline \multirow[t]{5}{*}{ B1 Economic } & C11 Automation cost & 0.036 \\
\hline & C12 Ground cost & 0.094 \\
\hline & C13 Personnel cost & 0.014 \\
\hline & C14 Maintenance cost & 0.029 \\
\hline & C15 Expansion cost & 0.009 \\
\hline \multirow[t]{5}{*}{ B2 Performance } & C21 Containers per hour & 0.003 \\
\hline & C22 Time for serving trucks & 0.004 \\
\hline & C23 Use of door & 0.008 \\
\hline & C24 Equipment inactivity rate & 0.038 \\
\hline & C25 Time of container permanence & 0.004 \\
\hline \multirow[t]{4}{*}{ B3 Capacity } & C31 Storage capacity & 0.001 \\
\hline & C32 Number of lanes per door & 0.003 \\
\hline & C33 Number of cranes per door & 0.001 \\
\hline & C34 Number of containers moved per hour & 0.009 \\
\hline \multirow[t]{3}{*}{ B4 Expansion } & C41 Expansion possibility & 0.022 \\
\hline & C42 Expansion complexity & 0.002 \\
\hline & C43 Expansion time & 0.002 \\
\hline \multirow[t]{3}{*}{ B5 Functionality } & C51 Automation level & 0.007 \\
\hline & C52 Usability & 0.022 \\
\hline & C53 Scenario change & 0.022 \\
\hline
\end{tabular}

First level criterion: safety and security

\begin{tabular}{llr}
\hline Second level criterion & Third level criteria & $\begin{array}{c}\text { Weight } \\
\left(W C G_{k}\right)\end{array}$ \\
\hline B6 Safety and Security & C61 Danger level of the DGs & 0.076 \\
& C62 DG amount & 0.042 \\
& C63 Distance to the urban core & 0.129 \\
C64 Equipment reliability & 0.011 \\
C65 Evacuation time & 0.043 \\
C66 Density of population & C67 Weather conditions & 0.024
\end{tabular}

First level criterion: environmental care

\begin{tabular}{llc}
\hline Second level criteria & Third level criteria & $\begin{array}{c}\text { Weight } \\
\left(W C G_{k}\right)\end{array}$ \\
& & 0.086 \\
\hline B7 Location & C71 Industrial ground availability & 0.031 \\
& C72 Flood risk & 0.027
\end{tabular}




\begin{tabular}{|c|c|c|}
\hline \multicolumn{3}{|c|}{ First level criterion: equipment performance } \\
\hline Second level criteria & Third level criteria & Weight $\left(W_{C G k}\right)$ \\
\hline \multirow[t]{5}{*}{ B9 Management } & C91 Energy efficiency & 0.013 \\
\hline & C92 Waste minimization & 0.005 \\
\hline & C93 Control of product transportation & 0.004 \\
\hline & C94 Preventive measures against pollution & 0.004 \\
\hline & C95 Water network distribution maintenance & 0.001 \\
\hline \multirow[t]{4}{*}{ B10 Construction } & $\begin{array}{l}\text { C101 Management of construction and demolition } \\
\text { residues }\end{array}$ & 0.011 \\
\hline & C102 Water consumption & 0.038 \\
\hline & $\begin{array}{l}\text { C103 Management of equipment, vehicles } \\
\text { and facilities }\end{array}$ & 0.005 \\
\hline & C104 Recovery of topsoil & 0.012 \\
\hline \multirow[t]{4}{*}{ B11 Emergency } & C111 Adsorbent material & 0.002 \\
\hline & C112 Procedures & 0.004 \\
\hline & C113 Training & 0.008 \\
\hline & C114 Weather & 0.001 \\
\hline
\end{tabular}

Table A2

Local normalized weight of the alternatives versus each third level criterion $\left(w_{a t k}\right)$ value for the alternatives for the third level criteria.

\begin{tabular}{|c|c|c|c|c|c|c|c|c|}
\hline Criterion & Alternative & $w_{\text {atk }}$ & Criterion & Alternative & $w_{a t k}$ & Criterion & Alternative & $w_{a t k}$ \\
\hline \multirow[t]{4}{*}{$\mathrm{C} 11$} & $\begin{array}{l}\text { A1 } \\
\text { A2 }\end{array}$ & $\begin{array}{l}0.0745 \\
0.2573\end{array}$ & C51 & $\begin{array}{l}\text { A1 } \\
\text { A2 }\end{array}$ & $\begin{array}{l}0.2672 \\
0.0385\end{array}$ & $\mathrm{C} 83$ & $\begin{array}{l}\mathrm{A} 1 \\
\mathrm{~A} 2\end{array}$ & $\begin{array}{l}0.0723 \\
0.2594\end{array}$ \\
\hline & A3 & 0.1403 & & $\mathrm{~A} 3$ & 0.0385 & & A3 & 0.1329 \\
\hline & A4 & 0.5006 & & A4 & 0.5186 & & A4 & 0.5058 \\
\hline & A5 & 0.0273 & & A5 & 0.1373 & & A5 & 0.0296 \\
\hline \multirow[t]{5}{*}{$\mathrm{C} 12$} & A1 & 0.2138 & C52 & A1 & 0.0919 & $\mathrm{C} 84$ & A1 & 0.1954 \\
\hline & A2 & 0.0578 & & A2 & 0.2039 & & $\mathrm{~A} 2$ & 0.0839 \\
\hline & $\mathrm{A} 3$ & 0.1071 & & A3 & 0.2039 & & $\mathrm{~A} 3$ & 0.0839 \\
\hline & A4 & 0.0310 & & A4 & 0.4694 & & A4 & 0.0387 \\
\hline & A5 & 0.5903 & & A5 & 0.0308 & & A5 & 0.5982 \\
\hline \multirow[t]{5}{*}{$\mathrm{C} 13$} & $\mathrm{~A} 1$ & 0.0862 & C53 & $\mathrm{A} 1$ & 0.0919 & C85 & $\mathrm{A} 1$ & 0.0919 \\
\hline & $\mathrm{A} 2$ & 0.2010 & & $\mathrm{~A} 2$ & 0.2039 & & $\mathrm{~A} 2$ & 0.2039 \\
\hline & A3 & 0.2010 & & A3 & 0.2039 & & $\mathrm{~A} 3$ & 0.2039 \\
\hline & A4 & 0.4691 & & A4 & 0.4694 & & A4 & 0.4694 \\
\hline & A5 & 0.0427 & & A5 & 0.0308 & & A5 & 0.0308 \\
\hline
\end{tabular}




\begin{tabular}{|c|c|c|c|c|c|c|c|c|}
\hline \multirow[t]{5}{*}{ C14 } & $\mathrm{A} 1$ & 0.0723 & C61 & $\mathrm{A} 1$ & 0.2998 & C91 & A1 & 0.4805 \\
\hline & A2 & 0.2594 & & A2 & 0.0453 & & A2 & 0.0727 \\
\hline & A3 & 0.1329 & & A3 & 0.0453 & & A3 & 0.0727 \\
\hline & A4 & 0.5058 & & A4 & 0.0949 & & A4 & 0.0727 \\
\hline & A5 & 0.0296 & & A5 & 0.5148 & & A5 & 0.3013 \\
\hline \multirow[t]{5}{*}{ C15 } & $\mathrm{A} 1$ & 0.0745 & C62 & $\mathrm{A} 1$ & 0.2615 & C92 & A1 & 0.2364 \\
\hline & A2 & 0.2573 & & A2 & 0.0634 & & A2 & 0.0876 \\
\hline & A3 & 0.1403 & & A3 & 0.1290 & & A3 & 0.0876 \\
\hline & A4 & 0.5006 & & A4 & 0.0333 & & A4 & 0.0876 \\
\hline & A5 & 0.0273 & & A5 & 0.5128 & & A5 & 0.5007 \\
\hline \multirow[t]{5}{*}{$\mathrm{C} 21$} & $\mathrm{~A} 1$ & 0.2944 & C63 & $\mathrm{A} 1$ & 0.0634 & C93 & A1 & 0.3085 \\
\hline & A2 & 0.0878 & & A2 & 0.2615 & & A2 & 0.0697 \\
\hline & A3 & 0.0964 & & A3 & 0.1290 & & A3 & 0.0697 \\
\hline & A4 & 0.0297 & & A4 & 0.5128 & & A4 & 0.0608 \\
\hline & A5 & 0.4917 & & A5 & 0.0333 & & A5 & 0.4913 \\
\hline \multirow[t]{5}{*}{$\mathrm{C} 22$} & $\mathrm{~A} 1$ & 0.0485 & C64 & $\mathrm{A} 1$ & 0.1223 & C94 & A1 & 0.5191 \\
\hline & A2 & 0.3967 & & A2 & 0.0529 & & A2 & 0.1429 \\
\hline & A3 & 0.3967 & & A3 & 0.0529 & & A3 & 0.1429 \\
\hline & A4 & 0.1098 & & A4 & 0.5140 & & A4 & 0.1563 \\
\hline & A5 & 0.0485 & & A5 & 0.2580 & & A5 & 0.0389 \\
\hline \multirow[t]{5}{*}{$\mathrm{C} 23$} & $\mathrm{~A} 1$ & 0.1347 & C65 & $\mathrm{A} 1$ & 0.0600 & C95 & A1 & 0.1342 \\
\hline & $\mathrm{A} 2$ & 0.2636 & & $\mathrm{~A} 2$ & 0.2150 & & A2 & 0.1342 \\
\hline & A3 & 0.4955 & & A3 & 0.2150 & & A3 & 0.1342 \\
\hline & A4 & 0.0682 & & A4 & 0.4779 & & A4 & 0.0346 \\
\hline & A5 & 0.0381 & & A5 & 0.0322 & & A5 & 0.5628 \\
\hline \multirow[t]{5}{*}{ C24 } & $\mathrm{A} 1$ & 0.0745 & C66 & $\mathrm{A} 1$ & 0.0634 & C101 & A1 & 0.0919 \\
\hline & $\mathrm{A} 2$ & 0.2573 & & A2 & 0.2615 & & $\mathrm{~A} 2$ & 0.2039 \\
\hline & $\mathrm{A} 3$ & 0.1403 & & $\mathrm{~A} 3$ & 0.1290 & & $\mathrm{~A} 3$ & 0.2039 \\
\hline & A4 & 0.5006 & & A4 & 0.5128 & & A4 & 0.4694 \\
\hline & A5 & 0.0273 & & A5 & 0.0333 & & A5 & 0.0308 \\
\hline \multirow[t]{5}{*}{$\mathrm{C} 25$} & A1 & 0.1511 & C67 & $\mathrm{A} 1$ & 0.3136 & $\mathrm{C} 102$ & A1 & 0.0919 \\
\hline & $\mathrm{A} 2$ & 0.0464 & & $\mathrm{~A} 2$ & 0.1093 & & A2 & 0.2039 \\
\hline & A3 & 0.0464 & & $\mathrm{~A} 3$ & 0.0553 & & A3 & 0.2039 \\
\hline & A4 & 0.2526 & & A4 & 0.0298 & & A4 & 0.4694 \\
\hline & A5 & 0.5036 & & A5 & 0.4920 & & A5 & 0.0308 \\
\hline \multirow[t]{5}{*}{ C31 } & A1 & 0.2043 & C71 & $\mathrm{A} 1$ & 0.2561 & $\mathrm{C} 103$ & A1 & 0.0993 \\
\hline & A2 & 0.0548 & & A2 & 0.0680 & & A2 & 0.2079 \\
\hline & A3 & 0.1062 & & $\mathrm{~A} 3$ & 0.1219 & & $\mathrm{~A} 3$ & 0.2079 \\
\hline & A4 & 0.0306 & & A4 & 0.0327 & & A4 & 0.4420 \\
\hline & A5 & 0.6041 & & A5 & 0.5213 & & A5 & 0.0430 \\
\hline \multirow[t]{2}{*}{ C32 } & $\mathrm{A} 1$ & 0.0485 & $\mathrm{C} 72$ & $\mathrm{~A} 1$ & 0.0723 & C104 & A1 & 0.2561 \\
\hline & A2 & 0.3967 & & A2 & 0.2594 & & A2 & 0.0680 \\
\hline
\end{tabular}




\begin{tabular}{|c|c|c|c|c|c|c|c|c|}
\hline & A3 & 0.3967 & & A3 & 0.1329 & & A3 & 0.1219 \\
\hline & A4 & 0.1098 & & A4 & 0.5058 & & A4 & 0.0327 \\
\hline & A5 & 0.0485 & & A5 & 0.0296 & & A5 & 0.5213 \\
\hline \multirow[t]{5}{*}{ C33 } & A1 & 0.2432 & C73 & $\mathrm{A} 1$ & 0.0845 & C111 & A1 & 0.1640 \\
\hline & A2 & 0.2432 & & A2 & 0.1976 & & A2 & 0.3627 \\
\hline & A3 & 0.2432 & & A3 & 0.1976 & & A3 & 0.3627 \\
\hline & A4 & 0.0270 & & A4 & 0.4897 & & A4 & 0.0818 \\
\hline & A5 & 0.2432 & & A5 & 0.0305 & & A5 & 0.0287 \\
\hline \multirow[t]{5}{*}{ C34 } & $\mathrm{A} 1$ & 0.0563 & C74 & $\mathrm{A} 1$ & 0.5040 & C112 & A1 & 0.1640 \\
\hline & A2 & 0.1092 & & A2 & 0.1079 & & A2 & 0.3627 \\
\hline & A3 & 0.1966 & & A3 & 0.1079 & & A3 & 0.3627 \\
\hline & A4 & 0.0331 & & A4 & 0.2482 & & A4 & 0.0818 \\
\hline & A5 & 0.6048 & & A5 & 0.0321 & & A5 & 0.0287 \\
\hline \multirow[t]{5}{*}{ C41 } & $\mathrm{A} 1$ & 0.0959 & C75 & $\mathrm{A} 1$ & 0.5040 & C113 & Al & 0.0535 \\
\hline & A2 & 0.2491 & & A2 & 0.1079 & & A2 & 0.3057 \\
\hline & A3 & 0.1442 & & A3 & 0.1079 & & A3 & 0.3057 \\
\hline & A4 & 0.4781 & & A4 & 0.2482 & & A4 & 0.3057 \\
\hline & A5 & 0.0327 & & A5 & 0.0321 & & A5 & 0.0293 \\
\hline \multirow[t]{5}{*}{ C42 } & $\mathrm{A} 1$ & 0.0959 & C81 & $\mathrm{A} 1$ & 0.0919 & C114 & A1 & 0.3117 \\
\hline & A2 & 0.2491 & & A2 & 0.2039 & & A2 & 0.0460 \\
\hline & A3 & 0.1442 & & A3 & 0.2039 & & A3 & 0.0460 \\
\hline & A4 & 0.4781 & & A4 & 0.4694 & & A4 & 0.1030 \\
\hline & A5 & 0.0327 & & A5 & 0.0308 & & A5 & 0.4933 \\
\hline \multirow[t]{5}{*}{ C43 } & $\mathrm{A} 1$ & 0.0959 & C82 & $\mathrm{A} 1$ & 0.0707 & & & \\
\hline & A2 & 0.2491 & & A2 & 0.1591 & & & \\
\hline & A3 & 0.1442 & & A3 & 0.1591 & & & \\
\hline & A4 & 0.4781 & & A4 & 0.5751 & & & \\
\hline & A5 & 0.0327 & & A5 & 0.0361 & & & \\
\hline
\end{tabular}




\section{References}

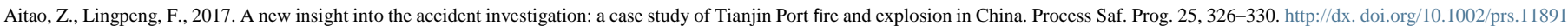
Alessandri, A., Cervellera, C., Cuneo, M., Gaggero, M., Soncin, G., 2008. Modeling and feedback control for resource allocation and performance analysis in container terminals. IEEE Trans. Intell. Transp. Syst. 9, 601-614. http://dx.doi.org/10.1109/ TITS.2008.2006737.

Al-Harbi, K.M.A.S., 2001. Application of the AHP in project management. Int. J. Proj. Manage. 19, 19-27. http://dx.doi.org/10.1016/S0263-7863(99)00038-1.

Aragonés-Beltrán, P., Chaparro-González, F., Pastor-Ferrando, J.-P., Pla-Rubio, A., 2014. An AHP (Analytic Hierarchy Process)/ANP (Analytic Network Process)-based multicriteria decision approach for the selection of solar-thermal power plant investment projects. Energy 66, 222-238. http://dx.doi.org/10.1016/j.energy.2013.12.016.

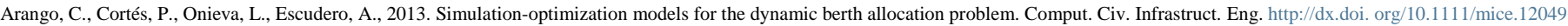

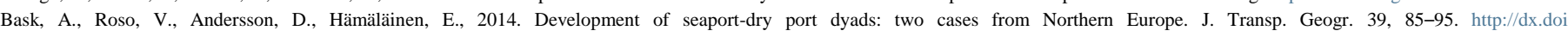
org/10.1016/j.jtrangeo.2014.06.014.

Bian, Z., Yang, Y., Mi, W., Mi, C., 2015. Dispatching electric AGVs in automated container terminals with long travelling distance. J. Coast. Res. 73, 75-81. http://dx.doi.org/ 10.2112/SI73-014.1.

Cascetta, E., Cartenì, A., Pagliara, F., Montanino, M., 2015. A new look at planning and designing transportation systems: a decision-making model based on cognitive rationality, stakeholder engagement and quantitative methods. Transp. Policy 38, 27-39. http://dx.doi.org/10.1016/j.tranpol.2014.11.005.

Cefic, 2011. Guidelines for Measuring and Managing CO2 Emission from Freight Transport Operations 19. < http://www.cefic.org/Documents/RESOURCES/ Guidelines/Transport-andLogistics/Best\%20Practice\%20Guidelines\%20\%20General\%20Guidelines/Cefic-ECTA\%20Guidelines\%20for\%20measuring $\% 20$ and $\% 20$ managing $\% 20 \mathrm{CO} \% 20$ emissions\%20from\%20transport\%20operations \%20Final\%2030.03.2011.pdf?epslanguage=en $>($ accessed 01.17 .18$)$.

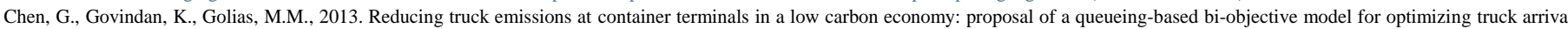
pattern. Transp. Res. Part E Logist. Transp. Rev. 55, 3-22. http://dx.doi.org/10.1016/j.tre.2013.03.008.

Clarkson Centre for business ethics, 1999. Principles of Stakeholder Management. The Clarkson Principles. The Clarkson Centre for Business Ethics, Toranto, Canada.

DESTINY project - Dangerous Goods, 2013. Int. union road-rail Comb. Transp. < http:// www.destiny-project.eu/dangerous-goods-to4leaflet-in-nine-languages/ > .

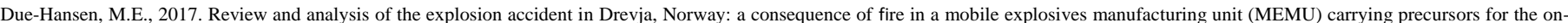
site production of bulk explosives. Saf. Sci. 96, 33-40. http://dx.doi.org/10.1016/j.ssci.2017.03.003.

European Union Road Federation, 2016. Road Statitics Yearbook, 2016. < http://www. erf.be/images/Statistics/ADprint-ERFSTATS2016.pdf > .

Eurostat, 2015. Archive:Transport accident statistics. < http://ec.europa.eu/eurostat/ statistics-explained/index.php/Archive:Transport_accident_statistics\#Railway_accident_statistics >(accessed $5.5 .17)$

Glickman, T.S., Erkut, E., 2007. Assessment of hazardous material risks for rail yard safety. Saf. Sci. 45, 813-822. http://dx.doi.org/10.1016/j.ssci.2006.09.004.

Gogas, M., Papoutsis, K., Nathanail, E., 2014. Optimization of decision-making in port logistics terminals: using analytic hierarchy process for the case of port of Thessaloniki. Transp. Telecommun. J. 15, 255-268. http://dx.doi.org/10.2478/ttj2014-0022.

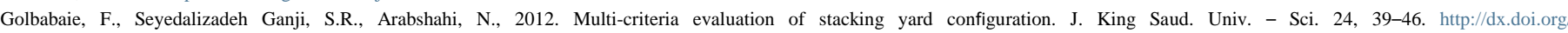
10.1016/j.jksus.2010.08.010

Guo, X., Huang, S.Y., 2012. Dynamic space and time partitioning for yard crane workload management in container terminals. Transp. Sci. 46, 134-148. http://dx.doi.org/10. 1287/trsc.1110.0383.

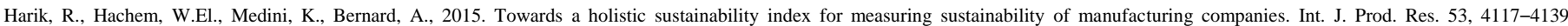
http://dx.doi.org/10.1080/00207543.2014.993773.

Hasan, M.H., Mahlia, T.M.I., Nur, H., 2012. A review on energy scenario and sustainable energy in Indonesia. Renew. Sustain. Energy Rev. 16, 2316-2328. http://dx.doi.org/ 10.1016/j.rser.2011.12.007.

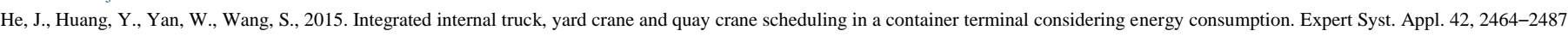
http://dx.doi.org/10.1016/j.eswa.2014.11.016.

HHLA Hamburger Hafen und Logistik AG, 2017. CO2 Emiss. per Stand. Contain. handled. < https://hhla.de/en/sustainability/overview/co2-emissions.html > (accessed 5. 18.17)

Ishizaka, A., Labib, A., 2011. Review of the main developments in the analytic hierarchy process. Expert Syst. Appl. 38, 14336-14345. http://dx.doi.org/10.1016/j.eswa. 2011.04.143.

Jahromi, A.R.M., Nooramin, A.S., Safaei, A.A., 2012. A combined extent fuzzy AHP and simulation method for selecting stacking layout type in marine container terminals Int. J. Serv. Oper. Manage. 12, 332-347. http://dx.doi.org/10.1504/IJSOM.2012. 047624.

Jin, J.G., Lee, D., Cao, J.X., 2016. Storage yard management in maritime container terminals. Transp. Sci. 50, 1300-1313. http://dx.doi.org/10.1287/trsc.2014.0527.

Kang, S., Medina, J.C., Ouyang, Y., 2008. Optimal operations of transportation fleet for unloading activities at container ports. Transp. Res. Part B Methodol. 42, 970-984. http://dx.doi.org/10.1016/j.trb.2008.02.003.

Kayikci, Y., 2010. A conceptual model for intermodal freight logistics centre location decisions. Proc. - Soc. Behav. Sci. 2, 6297-6311. http://dx.doi.org/10.1016/j.sbspro. 2010.04.039.

Koppe, B., Brinkmann, B., 2008. State of the art of handling and storage systems on container terminals. In: Chinese-German Joint Symposium on Hydraulic and Ocean Engineering, pp. 57-61.

Lee, B.K., Kim, K.H., 2013. Optimizing the yard layout in container terminals. OR Spectr. 35, 363-398. http://dx.doi.org/10.1007/s00291-012-0298-z.

Linstone, H.A., Turoff, M., 1975. The Delphi Method - Techniques and applications. Delphi Method - Tech. Appl., pp. 1-616. http://doi.org/10.2307/1268751.

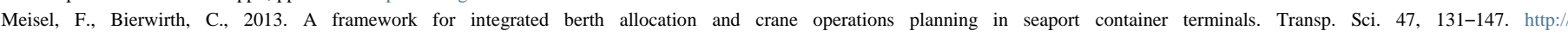
dx.doi.org/10.1287/trsc.1120.0419.

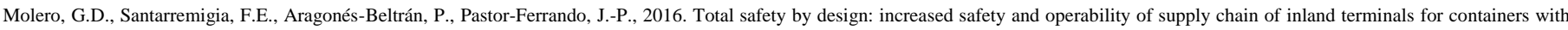
dangerous goods. Saf. Sci. http://dx.doi.org/10.1016/j. ssci.2016.10.007.

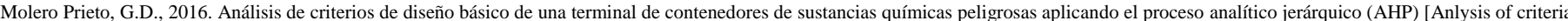
for the basic design of a container terminal of hazardous goods applying Analytic Hierarchy Process (AHP)]. Universitat Politècnica de València, Valencia (Spain). http://doi.org/10.4995/Thesis/10251/61773.

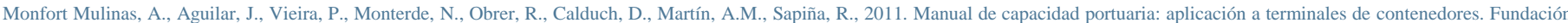
Valenciaport ISBN: 9788493815561.

Montesinos-Valera, J., Aragonés-Beltrán, P., Pastor-Ferrando, J.-P., 2017. Selection of maintenance, renewal and improvement projects in rail lines using the analytic network process. Struct. Infrastruct. Eng. 1-21. http://dx.doi.org/10.1080/ 15732479.2017.1294189.

Mulliner, E., Malys, N., Maliene, V., 2016. Comparative analysis of MCDM methods for the assessment of sustainable housing affordability. Omega 59, 146-156. http://dx doi.org/10.1016/j.omega.2015.05.013.

Murdoch, D., Tozer, D., 2012. A master's guide to: Container securing, 2nd ed. The Standard Club and Lloyd's Register, London.

National Bureau of Statistics of China - National Data, 2017. < http://data.stats.gov.cn/ english/easyquery.htm?cn=C01 >(accessed 5.16.17).

Peilin, Z., Jian, M., Long, Y., 2012. Research on Layout Evaluation Indexes System of Dangerous Goods Logistics Port Based on AHP. In: In: Wu, Y. (Ed.), Software Engineering and Knowledge Engineering: Theory and Practice, vol. 2. Springer, Berlin, Heidelberg, pp. 943-949 doi:10.1007/978-3-642-25349-2_125.

Reynolds, S.J., Schultz, F.C., Hekman, D.R., 2006. Stakeholder theory and managerial decision-making: constraints and implications of balancing stakeholder interests. J. Bus. Ethics 64, 285-301. http://dx.doi.org/10.1007/s10551-005-5493-2. 


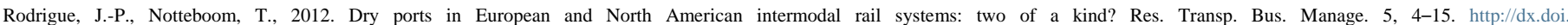
org/10.1016/j.rtbm.2012.10.003.

Roso, V., Woxenius, J., Lumsden, K., 2009. The dry port concept: connecting container seaports with the hinterland. J. Transp. Geogr. 17, 338-345. http://dx.doi.org/10.

1016/j.jtrangeo.2008.10.008.

Roy, B., Słowiński, R., 2013. Questions guiding the choice of a multicriteria decision aiding method. EURO J. Decis. Process. 1, 69-97. http://dx.doi.org/10.1007/ s40070-013-0004-7.

Saaty, T.L., 1980. The Analytic Hierarchy Process, Planning, Priority Setting, Resource Allocation. McGraw-Hill, New York.

Saaty, T.L., 1987. The analytic hierarchy process: what it is and how it is used. Math. Model. 9, 161-176. http://dx.doi.org/10.1016/0270-0255(87)90473-8.

Saaty, T.L., 2006. Rank from comparisons and from ratings in the analytic hierarchy/ network processes. Eur. J. Oper. Res. 168, 557-570. http://dx.doi.org/10.1016/j. ejor.2004.04.032.

Saaty, T.L., 2013. The analytic network process. Decis. Mak. Anal. Netw. Process 195, 1-40. http://dx.doi.org/10.1007/978-1-4614-7279-7_1.

Saaty, T.L., 2016. The Analytic Hierarchy and Analytic Network Processes for the Measurement of Intangible Criteria and for Decision-Making, pp. 363-419. http:// doi.org/10.1007/978-1-49393094-4_10.

Saaty, T.L., Ozdemir, M.S., 2003. Why the magic number seven plus or minus two. Math. Comput. Model. 38, 233-244. http://dx.doi.org/10.1016/S0895-7177(03)90083-5.

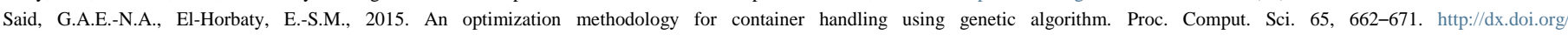
10.1016/j.procs.2015.09.010.

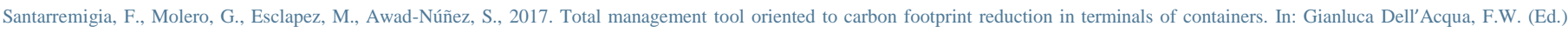
Transport Infrastructure and Systems: Proceedings of the AIIT International Congress on Transport Infrastructure and Systems (Rome, Italy, 10-12 April 2017). CRC Press, Taylor\&Francis Group, LLC, pp. 987-995.

Tramarico, C.L., Salomon, V.A.P., Marins, F.A.S., 2015. Analytic hierarchy process and supply chain management: a bibliometric study. Proc. Comput. Sci. 55, 441-450. http://dx.doi.org/10.1016/j.procs.2015.07.005.

UNCTAD, 2016. Review of maritime transport 2016. United Nations.

United States Department of Transportation - Bureau of Transportation Statistics, 2017.

Freight Anal. Framew. < http://faf.ornl.gov/faf4/Extraction1.aspx > (accessed 5. 18.17).

US Department of Transportation PHMSA, 2017. Hazmat Intell. Portal. <https://hip. phmsa.dot.gov/analyticsSOAP/saw.dll? Dashboard >(accessed 5.18.17)

Velasquez, M., Hester, P.T., 2013. An analysis of multi-criteria decision making methods. Int. J. Oper. Res. 10, 56-66.

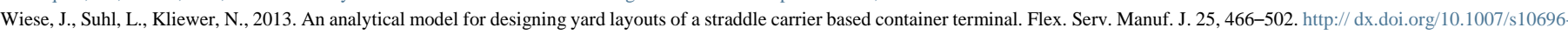
011-9132-1.

Yang, Y.C., 2015. Determinants of container terminal operation from a green port perspective. Int. J. Shipp. Transp. Logist. 7, 319. http://dx.doi.org/10.1504/IJSTL.2015. 069123.

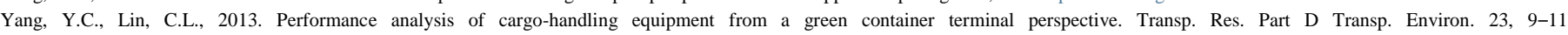
http://dx.doi.org/10.1016/j.trd.2013.03.009.

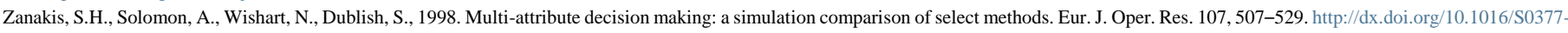
2217(97)00147-1.

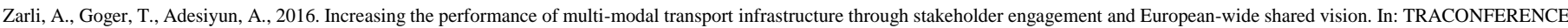
2016, Warsaw 18-21 April.

\section{Glossary}

$\begin{array}{ll}\text { AHP: } & \text { Analytical hierarchical process } \\ \text { CBA: } & \text { Cost-benefit analysis } \\ \text { CHE: } & \text { Container handling equipment } \\ \text { CR: } & \text { Consistency ratio } \\ \text { DGs: } & \text { Dangerous goods } \\ \text { GHG: } & \text { Greenhouse gas emissions } \\ \text { ITDG: } & \text { Inland terminals of containers with dangerous goods }\end{array}$

MCDM: Multicriteria decision making

RI: Random index TEU: Twenty-foot equivalent unit tkm: Tonne-kilometre

$W_{A t G}$ : Global normalized weight of alternative " $\mathrm{t}$ " related to the goal wati: Local normalized weight of alternative " $\mathrm{t}$ " versus the first level criterion " $\mathrm{i}$ " wati: Local normalized weight of alternative

" $\mathrm{t}$ " versus the second level criterion " $\mathrm{j}$ " watk: Local normalized weight of alternative " $\mathrm{t}$ " versus the third level criterion " $\mathrm{k}$ " WCGk: Global normalized weight of criterion " $\mathrm{k}$ " in the third level versus the goal $w_{c i}$ : Local (and global) normalized weight of a first level criterion " $\mathrm{i}$ " $w_{c j}$ : Local normalized weight of a second level criterion " $\mathrm{j}$ " $w_{c k}$ : Local normalized weight of a third level criterion " $\mathrm{k}$ " 